\title{
REFLEXÕES SOBRE UMA PROPOSTA DE ATENDIMENTO A CRIANÇAS DE ZERO A DOIS ANOS: AVALIANDO PROCEDIMENTOS PEDAGÓGICOS*
}

\author{
Cláudia Maria Simões Martinez**
}

\section{RESUMO}

Este artigo teve como objetivo analisar as oportunidades de interação da criança pequena, nas creches públicas, situadas em uma cidade de porte médio no interior do estado de São Paulo. Foi elaborado um roteiro de entrevistas semiestruturado dirigido à duas berçaristas que trabalham há mais de dez anos em duas creches, situadas em bairros distintos da cidade, com objetivo de conhecer a rotina de atividades com foco nas relações que as crianças estabelecem. Os dados foram analisados segundo uma abordagem qualitativa. Adotamos a relação pedagógica como eixo para identificar as ą̧ões educacionais que ocorrem ou poderiam ocorrer entre crianças e educadores. Os resultados mostram que é necessário rediscutir o conteúdo trabalhado junto às crianças, a forma como é ministrado e ainda considerar o perfil do profissional "berçarista" diante da rotina que se dá no cotidiano. São sugeridas reflexões sobre a estrutura e funcionamento do berçário em função da possibilidade de promoção do desenvolvimento infantil, neste contexto.

\section{INTRODUÇÃO}

Nossa intenção neste estudo foi a de realizar uma análise preliminar sobre as atuais propostas de atendimento à criança pequena, no contexto de duas creches públicas, a partir do relato de berçaristas e discutir algumas das suas implicações no desenvolvimento infantil.

Para refletir sobre as experiências das creches e suas propostas de atendimento à criança pequena nos pareceu fundamental abordar, numa breve introdução, temas vinculados ao desenvolvimento e à educação infantil.

Embora se reconheça que a Educação Infantil tenha recebido significativa atenção nas últimas décadas, em termos da legislação e na expansão do atendimento ao público, surgem preocupações relativas à qualidade destes atendimentos. Tem-se problemas de espaços inadequados, de ausência de propostas pedagógicas, de pessoas sem habilitação, dentre outros.

* Estudo apresentado no IV Simpósio Latino Americano de Atenção à Criança de Zero a Seis Anos e II Simpósio Nacional de Educação Infantil,Brasília, nov./96.

** Professora do Departamento de Terapia Ocupacional da Universidade Federal de São Carlos.

Paidéia, FFCLRP-USP, Rib. Preto, Fev/Ago 96. 
Neste sentido, reconhecemos a importância de se conceber e implementar uma política educacional, que abranja inclusive a faixa etária de $0-2$ anos, fundada em concepções pedagógicas que ultrapasssem o carater assistencialista. Tendo claro que é o sentido educativo que deve reger as práticas e propostas da creche perguntamos: quais seriam os procedimentos, por parte da instituição, que poderiam levar a uma educação da criança de 0 - 2 anos, não restrita ao aspecto formal, instrumental, metodológico e que estivesse principalmente centrada na base da formação do sujeito histórico crítico e criativo? (Demo, 1994:15)

$\mathrm{Na}$ tentativa de discutir as práticas educativas das crianças pequenas efetivadas no ambiente dos berçários passamos a explicitar alguns dos pressupostos teóricos que adotamos para este estudo.

Primeiramente, concordamos com Bowlby (1990, p.21) a respeito das limitações que ainda temos sobre como criar crianças sem perturbações emocionais:

"Creio que já sabemos muita coisa e, que, se pudermos aplicar nossos conhecimentos atuais ocorrerá um aumento substancial da felicidade humana e uma tremenda redução das doenças psicológicas. Entretanto seria absurdo supor que já temos tantos conhecimentos que podemos garantir que uma criança, se tiver tal ou tal experiencia, crescerá sem maiores dificuldades."

Feita esta consideração, passamos a explicitar que acreditamos que uma tarefa fundamental do ambiente para com a criança pequena nos seus primeiros anos de vida, reside em responder a essa de forma adequada às suas necessidades a fim de gerar um "sentimento de segurança " que a leve perceber o mundo como responsivo e confiável.

Nesta perspectiva, o socializador assume um papel fundamental. Através da interaçāo que vai se estabelecendo entre socializador-criança (num processo bidirecional) poderá ocorrer a formação de um vínculo afetivo de extrema relevância para as crianças nesta idade.

Acreditamos ainda que os vínculos poderão promover uma relação entre a criança e o ambiente (no seu sentido mais amplo) que poderá ser pedagógica.

Destacamos então a definição de Garcia (1982: 344) a respeito da relação pedagógica: "Chamamos de relação pedagógica o vínculo implícito em toda 
prática educativa que se estabelece entre uma parte ( pessoa, grupo, instituição, etc) que ensina e outra que aprende."

Nesta relação, a criança pequena vai sinalizar ao socializador o que necessita, através do choro, do sorriso, da vocalização, do olhar ... Padrões de interação que vão se estabelecendo entre o adulto e a criança, numa espécie de sintonia, de sincronia, onde o tempo para observar a criança, interagir com ela e compreender seus sinais e responder a eles, é uma das variáveis essenciais neste processo interativo.

Salientamos então as condições de trabalho, de formação do educador da creche neste processo interativo, nos primeiros anos de vida da criança, e ainda a importância de um arranjo ambiental, adotado pela creche, que possibilite à criança interagir no ambiente físico e social mais amplo.

A opção deste destaque se dá por acreditarmos que os cuidados que a criança recebe nos primeiros anos de vida têm importância vital para a sua saúde mental futura e que o desenvolvimento, em especial nesta faixa de idade ( 0-2 anos), tem uma estreita relação com a qualidade da interação que estabelece com seus socializadores, sejam eles familiares ou os da instituição de cuidado diário que frequenta.

Assim, construimos este texto como uma proposta de reflexão sobre a relação pedagógica que se estabelece entre a criança e a berçarista nos momentos de sua permanência na creche.

A partir do relato das berçaristas, pretendemos identificar as situações de interação que podem ou poderiam levar ao desenvolvimento afetivo, cognitivo e social da criança.

Pretendemos ao final chegar a um equacionamento de questões que permita colocar em evidência formas de aprimorar o atendimento à crianças pequenas nos ambientes institucionais que convivem.

\section{O CAMINHO PERCORRIDO}

Como ponto de partida, elaboramos e aplicamos um roteiro de entrevista semi-estruturado com núcleos de questões relativos à rotina de atividades que se dá no cotidiano do berçário.

As entrevistas foram efetivadas com duas berçaristas que trabalham há mais de dez anos no berçário de duas creches, localizadas em bairros distintos, em uma cidade de porte médio no interior do estado de São Paulo. As entrevistas foram gravadas em fitas $\mathrm{k} 7 \mathrm{com}$ a duração média de uma hora e foram transcritas na íntegra. Os dados foram analisados segundo uma abordagem qualitativa.Para 
tanto foi necessário eralizar várias leituras do material e contar com amis um pesquisador, buscando-se concordância nas informações analisadas.

\section{RESULTADOS}

\begin{tabular}{|l|l|l|l|}
\hline Berçário 1 & $\begin{array}{l}\text { 24 Crianças- 4 } \\
\text { Meses Até 2 Anos } \\
\text { e Meio. }\end{array}$ & 02 Berçaristas & $\begin{array}{l}\text { Sala Ampla, Berços } \\
\text { dispostos em sequência, } \\
\text { Banheiro, Pia, Trocador, } \\
\text { Penicos e Vasos Sanitários. }\end{array}$ \\
\hline Berçário 2 & 30 Crianças & $\begin{array}{l}\text { 04 Berçaristas } \\
\text { Estando uma em } \\
\text { Férias no } \\
\text { Momento. }\end{array}$ & Idem \\
\hline
\end{tabular}

\section{FUNCIONAMENTO}

Foi através da descrição do funcionamento dos berçários, relatados pelas educadoras que procuramos captar os episódios de interação que podem ou poderiam levar a ações educativas.

\section{A interação mãe-berçarista.}

2. A interação berçarista-criança.

\section{MOMENTOS DA CHEGADA}

\section{A INTERAÇÃO MÃE-BERÇARISTA}

“Depende assim...tem mãe que quando tem algum problema, ou quando ela tem algum remédio, traz pro horário do remédio, fala alguma coisa, conversa. As vezes quando tá com pressa, entrega e já vai né? geralmente elas tão sempre com pressa prá entrar no servico né..."

Na situação acima descrita, valorizamos as oportunidades de interação entre as partes - família/creche - onde há possibilidade de troca de informações. 


\section{ADENTRANDO À CRECHE: O INICIO DE UM NOVO DIA}

\section{A INTERAÇÃO BERÇARISTA - CRIANÇA}

“...na hora que chega é aquela choradeira porque tira da mãe né? Tem uns que não, que já entra, já dá beijo na gente, senta lá no cantinho, porque as faxineiras estão limpando, até esperar elas terminar de limpar prá fazer xixi. Mas é assim, já tão acostumado. Agora os mais novo que vão chegando esses...que nem tem 3 que entrou esses dias né? Então eles tão tudo chorando lá. Mas na hora de dormir eles dorme e aí eles acordam mais bonzinho..."

A situação do ingresso da criança na creche tanto ao nível do cotidiano como nos momentos iniciais que vive quando passa a compor o grupo de crianças pode ser otimizada se um arranjo ambiental, planejado para acolher a criança que adentra à instituição, é realizado. Destacamos assim a integração inicial da criança na creche (processo de adaptação) como um momento que deve ser incluido no planejamento das atividades pedagógicas da creche.

\section{ALIMENTAÇÃO}

" Eu ponho assim no carrinho de 2, 3, e aí eu ponho os pratinho em cima da mesa e vou dando, dando até acabar. Aí termina aqueles e já pega os outros, é de 3 em 3 a gente vai dando. É prá adiantar porque se for prá dar prá um só ...até que eles mastiga... até que engole demora né? Então até agora eu pedi: tem que ir alguém lá prá ajudar neste horário, é difícil porque ele tão com sono então eles choram muito né?"

Destacamos neste trecho acima transcrito a importância de se assegurar um momento com tranquilidade para a atividade de alimentação.

\section{BRINCADEIRAS}

“Eu gosto dessa hora, não só lá. É a hora da atividade. Coloca no sol, um dia tá aqui na televisão, prá assistir um pouquinho de desenho...né os maiorzinho gosta de assistir né. As veiz a gente põe ali no quadrado cimentado, ali eles tomam sol. a gente põe eles prá gatinhar, prá ficar mais solto, porque lá dentro é muito preso. Então é a hora melhor que dá prá ter mais contato. Porque a parte da tarde geralmente não dá.". 
"A hora que a gente tem um tempinho a gente sempre brinca também. Canta, conversa...é duro, mas a gente sempre acha (um tempo), mas tem dia que não dá não... Que nem depois da janta eles tão tudo trocadinho, que a gente tem um tempinho, nós, nós deita lá com ele no chão e faz bicicleta e dança e faiz ginástica, e eles deita tudo com as perninhas prá cima sabe? E faz ginástica também...tudo isso nós faiz com eles, quando tem tempo né? Não é todo o dia que dá . Tem dia que não dá."

Notamos que os momentos de brincadeiras ocorrem (como diz a berçarista) "quando dá". Não percebemos um arranjo, uma organização que contemple o momento de brincadeiras inserido numa proposta de atividades cotidianas. Assim, destacamos aqui, a relevância de se prover as oportunidades de brincadeiras no contexto da creche. Destacamos ainda, a necessidade de se obter recursos ( brinquedos, formação do educador, número adequado de educadores...) para se ter condições de propiciar situações de brincadeiras, não apenas "quando dá tempo".

\section{SONO}

" porque o berçário junto atrapalha. Porque o nenê ele não faz o horário que o outro maior faz, é outra sequência, então ele acorda, geralmente acorda chorando ele quer mamadeira ou ele quer... e o outro tá ali, de dois ano, ele deita e dorme mesmo! Só que o menor não deixa ele dormir né?"

As oportunidades de sono não devem ser discutidas separadamente das outras que vimos estudando. Neste sentido, o arranjo ambiental que permita à criança dormir com tranquilidade durante seu período de permanência no berçário, deve ser pensado para o local.

\section{BANHO}

Chamamos atenção para as diferenças de funcionamento das 2 creches no que se refere ao banho:

“...ai eu saio pro meu almoço. Aí a outra, entra ela já vai tirando eles do penico, aqueles que já vão fazendo...já vai tirando ...fica em duas (berçaristas) né? Aí já vai brincando com eles e a outra vai acabando terminando o banho, porque tem bastante (criança) né? 
"Aí eu começo o banho. Ali por uma e meia duas horas... a gente começa a dar banho. Porque geralmente eu tô sozinha nesse horário, porque a outra (berçarista) sai as onze e entra a uma( hora) prá ajudar...eu tô sozinha, os (nenês) ficam no berço. Ficam no berço, mamam e ficam ali até as tias chegá. Porque ai chega uma que entra a uma e depois duas e meia chega a outra que o horário dela é duas e meia. Aí a gente vai dando banho. Porque o banho quando for umas dez. vinte prás quatro a gente tem que tá terminado né? Então tem que começar a uma hora... tem que ser rápido né? Uma lava e a outra troca... Gostam, iii a hora que eles mais gostam é a do banho. mas não dá tempo assim de ficar conversando. A gente precisaria ter mais tempo de conversar com eles mas é muita criança não dá né? Não dá prá você dar muita atencão. A gente fica olhando, conversa com eles né? Ensina... a gente procura conversar bastante, mas assim, é muito corrido. Muita criança, não dá tempo.

... então, você tá dando banho. eles estão correndo lá no banheiro porque lá tem banheiro tem escada, né. Eles tão subindo no berco. então você tem que ter aquela...tem que olhar tudo ao mesmo tempo. dá banho trocá..."

Os relatos das berçaristas acima descritos revelam elementos que permitem discutir como cada uma das as atividades ocorrem no dia a dia. Notamos diferenças marcantes entre as duas creches:

Creche 1.: Uma berçarista dá o banho e troca a criança enquanto a outra brinca com as crianças que ainda não tomaram banho e as que já estão prontas.

Creche 2.: Uma das berçaristas dá o banho e a outra troca a criança. Colocam no chão ou nos berços para brincar.

"Aí depois que eles tomam banho eles ficam ali brincando né...os grandinhos porque os bebês voltam pro berço...então porque precisaria...já foi até falado o berçário precisaria ser separado, os bebês dos maiorzinhos. Porque eu não posso colocar os bebês que engatinha no chão junto com os outros. Porque se eu tô dando banho e as outras duas trocando a gente não têm aquela atenção. Eles derrubam, passsam por cima... mordem, batem na cabeça do outro... E você dando banho você não pode parar toda hora se não não dá... Então eles acabam voltando pro berço coitados né?"

Paidéia, FFCLRP-USP, Rib. Preto, Fev/Ago 96. 
Notamos:

* No caso 1 um caráter mais individualizado na atividade como um todo.

* Maior tempo de contato entre berçarista e criança maior possibilidade de trocas afetivas para:

- criança que está sendo banhada.

- crianças que estão com um adulto em situação de brincadeira.

* Destacamos a necessidade de um número de educadores que seja suficiente para o desenvolvimento de cada atividade no berçário.

\section{MOMENTOS DA SAÍDA: À ESPERA DOS PAIS}

\section{RELAÇÃO MÃE - BERÇARISTA: VOLTANDO PARA CASA.}

" tem pais que são legal e chega contentinho e cumprimenta a gente e se a criança não tá bem a gente fala e aceita e já temuns que não gosta que a gente fala: ah sua criança tá com diarréia...tem até uma (criança) que não tá vindo. Eu cheguei a falar a criança tá doente precisa levar no médico e ela (a mãe) achou ruim e falou: a criança não tá doente!"

“...eu não sei se é falta de instrução ou se ela é mesmo ignorante, estúpida né? Eu virei para ela (para a mãe) e falei: ó eu não tô falando nada, eu só tô te avisando (que a criança está com diarréia) porque você pediu...Pediu prá que qualquer sinal diferente dela eu avisar..porque agora vai prá casa , já leva ela e as veiz a parte da noite é mais dificil prá socorrer."

“ A maioria (das mães) não pergunta como a criança passsou o dia. São poucas que perguntam. tem uma ai que a criança fica doente aí, as veiz fica de semana...fica com aquele ouvido vasando aquela infecção, você fala leva no médico, e elas nem lligam...sara assim coitadinho, por si mesmo...

"Tem aqueles (pais) que dá 7 da noite e ainda a criança tá aqui. $\mathrm{OH}$, tem criança que as veiz você precisa levar em casa. Ah eu esqueci, eu esqueci (imita a voz da mãe) eu perdi hora. mas direto assim?".

Ao pretendermos identificar os procedimentos educacionais levados a efeito pelos educadores da creche para com a criança pequena, não poderíamos deixar de "olhar" primeiramente para a relação mãe-berçarista que se dá no cotidiano, em especial nos momentos de entrada e saída da criança na instituição.

Esta escolha se dá por acreditarmos que as relações de troca de 
informações, de diálogo, de parceria entre membros da família e o educador que trabalha diretamente com a criança, em especial na faixa entre 0 - 2 anos, podem levar a ações mais acertivas em direção a um desenvolvimento adequado.

Ao abordarmos a relação dialógica, entre os socializadores da criança da instituição e os da família, temos a preocupação em valorizar a importância de levar a efeito relações mais humanas e respeitosas entre as partes por aumentar a compreensão e os significados dos valores que cada uma das partes (família e instituição) adota e que nem sempre vão no mesmo sentido. "Aprender a compreender, conviver e crescer com a diversidade é tornar-se um sujeito mais humano e mais generoso.( Giroux, 1986).

Acreditamos que a relação que se estabelece entre mães e berçaristas no momento de entrada e saída da criança na instituição, é carrregada de questões vinculadas à linguagem e ao poder, camufladas ou explicitadas em diferentes níveis na relação cotidiana. Para exemplificar, equacionamos as seguintes situações:

a) Diferenças de valores adotados pela família $X$ valores adotados pela creche.

b) Qual a visão das mães e das educadoras sobre o que é a creche: um direito? um favor?

c) As necessidades da família $X$ atendimento que a creche oferece.

Assim, as ações ou procedimentos educativos passam a nosso ver por questões afetivas entre a criança e seus socializadores e também entre os próprio socializadores. Neste último caso, onde estamos nos referindo às oportunidades de se estabelecer um relação segura e de confiança, as questões de valores assumem especial destaque pois é onde uma parte conhece a outra: levantamos então a questão da alteridade.

Num segundo momento olhamos para as relações que se estabelecem entre berçarista - criança nas atividades cotidianas no berçário. Tamanha pode ser a riqueza das experiências para as crianças e seus educadores ao longo de um dia! Mas podemos considerar as atividades de alimentação, banho, vestuário como atividades educacionais?

Consideramos que sim, pois a necessidade da criança - independente da natureza da atividade que vivencia - é a de estabelecer trocas afetivas e neste sentido levantamos questões relacionadas ao aspecto educativo das atividades:

1. O que se faz?

2. Como se faz?

3. Com qual objetivo se faz?

Paidéia, FFCLRP-USP, Rib. Preto, Fev/Ago 96. 
As três questões acima esboçadas nos levam a discutir primeiramente o conteúdo que é veiculado no cotidiano junto às crianças pequenas : o que se faz? Entendemos que o conteúdo deve estar inserido numa proposta ou projeto educativo que reflete uma determinada opção ideológica. No presente estudo destacamos o tipo de vínculo que tal projeto pressupõe entre o educador e a criança.

Como se faz? A questão remete por um lado às condições materiais para implementar tal projeto e, de outro à formação do educador uma vez que este é o mediador entre o "mundo"e a criança inserida numa instituição.

Com qual objetivo se faz? Esta terceira pergunta passa pela articulação do projeto educacional com a operacionalização de seus objetivos: $O$ educador conhece o projeto escolhido? Está o educador da creche afinado com o projeto escolhido? O educador em seu cotidiano tem liberdade para a criação, nas tarefas que surgem de forma a refletir sobre as situações e tomar decisões frente a elas de modo não esterotipado?

Acreditamos que todo momento em que se têm claro os propósitos educacionais de cada ação e as condições de efetivá-las, se constitui em oportunidades potenciais para educar, seja na atividade de alimentação, banho, brincadeiras, vestuário dentre outras que ocorrem no cotidiano e que dependem de um arranjo ambiental (estruturação da rotina, formação do educador, condições físicas do local...) para se constituirem em atividades educativas.

Conforme havíamos proposto no início do presente estudo, o momento final deste se constitui no equacionamento das questões que levem à melhoria do atendimento educacional à crianças pequenas dos berçários estudados. Salientamos que as dimensões ora assumem um caráter mais explicíto ora implícito:

1. Nossa concepção de educador vê no profissional "auxiliar de creche" um educador.

2. Este educador tem tarefas complexas que podem se tornar pedagógicas.

3. Há necessidade de um número maior de profissionais nos berçários estudados, para possibilitar a interação do educador com a criança.

4. Acreditamos nos bons resultados que uma boa formação e o aprimoramento do educador possa trazer à criança, sua família, à instituição e a ele próprio.

5. Faz-se necessário estudar a estrutura e funcionamento dos berçários, com foco num processo interativo entre criança-educador de forma mais individualizada. 
Embora os resultados deste estudo remetam à relação berçarista -criança e berçarista-família de forma mais declarada reconhecemos a importância de se estudar a relação berçarista-instituição que se dá em diferentes níveis. Temos a preocupação de registrar que nossa postura não é a de acusar os profissionais berçaristas/educadoras - de má preparação (ainda que verdadeira em várias situações em nosso país). Consideramos que os profissionais estão inseridos numa estrutura administrativa vertical do sistema educacional. E, nas palavras de Garcia (1982, p.349)

“...é a instituição que configura o tecido onde se ajustam os estereótipos ( entendido como um conjunto de condutas fixas que se repetem ciclicamente embora já não satisfaçam a nenhuma necessidade específica da tarefa) e que possibilita e reforça determinado tipo de vínculo enquanto dificulta outros."

Tendo como pontos críticos as dimensões assinaladas, atentamos para a necessidade da produção de conhecimentos acerca dos processos educativos levados a efeito com a criança pequena no contexto das creches, na sua divulgação e implementação.

\section{REFERÊNCIA BIBLIOGRAFICA}

BOWLBY, J. Formação e rompimento dos laços afetivos. 2a. Edição. São Paulo, Martins Fontes, 1990.

DEMO, P. Educação e Qualidade. Campinas,SP:Papirus, 1994.

GIROUX, H. Teoria crítica e resistência em educação. Petrópolis, Vozes, 1986.

GARCIA, G. A relação pedagógica como vínculo libertador. Uma experiência de formação docente. IN: Introdução à psicologia escolar. Maria Helena Souza Patto (Org.). São Paulo: Queiroz, 1982. 342-360.

Paidéia, FFCLRP-USP, Rib. Preto, Fev/Ago 96. 


\section{ABSTRACT}

This paper aims to analyse the opportunities of the child interaction in day care centers in a medium size town in the State of São Paulo/ Brazil. We have elaborated and used one regulation of semi-strucutred interviews directed to two caretaker (caregivers) that have been working in two day care centers for more than ten years, in order to know the educational proposal and activities routine. We have adopted the educational relationship as the axix to identify the educational actions that occur or could occur among children and educators. The results show that it is necessary to review the subject worked with the children, the way it is employed and to consider the caretaker professional profile in the dayle activities routine. Relfections about the structure and running of the day care center related to the possibility of stimulating the child development have been proposed in this context.

Key words: day care center, caretaker ou caregiver, educational pratices, child development.

Palavras chave: creche, educadora, praticas educativas, desenvolvimento infantil. 